\title{
Effect of Citrus aurantium L. Essential Oil and Its Interaction with Fluoxetine on Anxiety in Male Mice
}

\author{
Sorin Saketi', Maryam Bananej1, Mahsa Hadipour Jahromy ${ }^{2 *}$ \\ ${ }^{1}$ Biology Department, Faculty of Biological Sciences, Islamic Azad University, North Tehran Branch, Tehran, Iran \\ ${ }^{2}$ Medical Sciences Research Centre, Tehran Medical Sciences Branch, Islamic Azad University, Tehran, Iran \\ Email: ${ }^{\text {jahromymh@yahoo.com }}$
}

Received 13 May 2014; revised 19 June 2014; accepted 2 July 2014

Copyright (C) 2014 by authors and Scientific Research Publishing Inc.

This work is licensed under the Creative Commons Attribution International License (CC BY). http://creativecommons.org/licenses/by/4.0/

(c) (i) Open Access

\begin{abstract}
Anxiety is a very common mental disorder among neurological diseases. Some herbs have soothing effects and play an important role in reducing anxiety. The purpose of this study is to investigate the effect of Citrus aurantium L. essential oil on anxiety and its interference with serotonergic pathway. Sixty male mice were assigned into control, sham (saline and olive oil), and experimental groups. Intraperitoneal injection of Citrus aurantium L. essential oil was applied at doses of 0.5, 2.5, and 5 percent for 5 days. In another set of experiments, after intraperitoneal injection of $\mathrm{Ci}$ trus aurantium L. essential oil at doses of $0.5,2.5$, and 5 percent for 5 days, on the $5^{\text {th }}$ day, 30 minutes before applying essential oil, fluoxetine $(2 \mathrm{mg} / \mathrm{kg})$ was injected. Then, the anxiety-related behavior was assessed using elevated plus maze test. The results revealed that injection of essential oil of Citrus aurantium L. alone or along with fluoxetine led to increasing the number of entries into the open arms and the time spent in open arms that was significantly different compared with control and sham groups $(P<\mathbf{0 . 0 0 1})$. Besides, further effects revealed when fluoxetine added to essential oils, however no more effects obtained when compared to fluoxetine alone. It is concluded that Citrus aurantium L. essential oil can reduce the anxiety in male mice and due to fluoxetin potentiation and maximum response observed, the herb may express its anxiolytic effects in part, via serotonergic system.
\end{abstract}

\section{Keywords}

Anxiety, Essential Oil, Citrus aurantium L., Fluoxetine

\footnotetext{
${ }^{*}$ Corresponding author.
} 


\section{Introduction}

Anxiety is a very common mental disorder. Stressful life events are one of the causes of anxiety [1]. There are some effective medicinal and behavioral treatments for anxiety. Antianxiety effects of various medicines applying in different treatment methods have been investigated. It is believed that selective serotonin reuptake inhibitors (SSRIs) such as fluoxetine, citalopram, paroxetine, are appropriate substitutes for traditional treatments of anxiety [2].

Serotonin, a neurotransmitter exists in the brain neurons, also known as 5-hydroxytryptamine (5-HT) possesses several roles in maintaining normal physiological functions [3]. Serotonergic system is involved in expressing fear and anxiety. Fluoxetine is one of the antagonists of 5-HT3 receptors that is effective in treatment of acute depression (including children's depression), phobia disorder (among children and adults), and obsessivecompulsive disorder [4].

Many traditional herbs such as the family of rutaceae, is known to have beneficial effects on anxiety for many years [5]. The effects of brewed and boiled flowers and leaves of the family of rutaceae have been studied to treat nervous system disorders [6]. They are very helpful in reduction of anxiety and insomnia symptoms, and recently Citrus aurantium L. is suggested as a medication for depression [6]. The results of analytical chemistry have shown that Citrus aurantium L. contains phenolic compounds and flavonoids that possess antioxidant, anticonvulsant, and anticancer properties [5].

Therefore, in this study anxiolytic effect of Citrus aurantium L. along with fluoxetine as a 5-HT receptor modulator was investigated on adult male mice in elevated plus maze test.

\section{Methods and Materials}

\subsection{Animals}

Male albino mice weighed 22 to $28 \mathrm{~g}$ supplied from Pasteur Institute were used in this study. The mice were kept in animal room of the Medical Faculty of Baghiatallah University. Sixty mice were assigned into 10 groups of six. Animals housed under the following laboratory conditions: temperature $22^{\circ} \mathrm{C} \pm 11^{\circ} \mathrm{C}$, humidity $40 \%-60 \%$, $12 \mathrm{~h} \mathrm{Light/Dark} \mathrm{cycle,} \mathrm{lights} \mathrm{on} \mathrm{at} \mathrm{07:00} \mathrm{h.} \mathrm{Mice} \mathrm{were} \mathrm{maintained} \mathrm{in} \mathrm{polyethylene} \mathrm{cages} \mathrm{with} \mathrm{enough} \mathrm{food} \mathrm{and}$ water available ad libitum. All measurements were performed between 9:00 and 15:00 h in the animal testing room. Mice were treated in accordance with the National Institutes of Health (NIH) Guide for Care and Use of Laboratory Animals.

\subsection{Essential Oil Preparation}

Collected Citrus aurantium L. flowers were bought from local market of Shiraz and dried in darkness and pulverized. $300 \mathrm{~g}$ of the dried powder were extracted with maceration. Essential oil was collected using $\mathrm{n}$-hexane and sodium sulfate, then, exposure to open air till n-hexane vaporized. The oils were kept in a cool place till used $(35 \% \mathrm{~W} / \mathrm{V})$. The essential oil dissolved in olive oil to make different concentrations of $0.5,2.5$, and 5 percent.

\subsection{Drugs and Treatments}

Fluoxetine was supplied from Damavand-Darou Company and injected intraperitoneally, using sodium chloride $9 \%$ (normal saline).

Intraperitoneal injection of Citrus aurantium L. essential oil was applied for the experimental group at doses of $0.5,2.5$, and 5 percent at a certain hour for 5 days. According to different studies and based on our previous experimental experiences, it is decided to use low dose of fluoxetine $(2 \mathrm{mg} / \mathrm{kg})$ that shows anxiolytic effects, and thirty minutes interval for injections. Therefore, in another set of experiments, after intraperitoneal injection of Citrus aurantium L. essential oil at doses of $0.5,2.5$, and 5 percent for 5 days, on the $5^{\text {th }}$ day, 30 minutes before applying the last injection of essential oil, fluoxetine $(2 \mathrm{mg} / \mathrm{kg})$ was injected to evaluate its modulator action. Thirty minutes after the injection of essential oil of Citrus aurantium L., the anxiety-related behavior of mice was assessed using elevated plus maze (EPM) test.

\subsection{EPM Test}

The studies were carried out on mice according to the method of Lister [7]. The plus-maze apparatus was made 
of Plexiglas and consisted of two open $(30 \times 5 \mathrm{~cm})$ and two closed $(30 \times 5 \times 15 \mathrm{~cm})$ arms. The arms extended from a central platform of $5 \times 5 \mathrm{~cm}$. The apparatus was mounted on a Plexiglas base raising it $38.5 \mathrm{~cm}$ above the floor. The test consisted in placing a mouse in the center of the apparatus (facing a closed arm) and allowing it to freely explore. All experiments recorded using personal camcorder. The number of entries into the open arms and the time spent in these arms were scored for a 5-min test period. An entry was defined as placing all four paws within the boundaries of the arm. The following measures were obtained from the test: the total number of arm entries; the percentage of arm entries into the open arms; the time spent in the open arms expressed as a percentage of the time spent in both the open and closed arms. Anxiolytic activity was indicated by increases in time spent in open arms or in number of open arm entries. Total number of entries into either type of arm was used as a measure of overall motor activity.

\subsection{Statistical Analysis}

All values were expressed as mean \pm SEM from six animals. The results were subjected to statistical analysis using Unpaired-t test to calculate the significance difference if any among the groups. $P<0.05$ was considered significant (Origin IV software).

\section{Results}

Figure 1 illustrates that in terms of the applied doses, the intraperitoneal injection of the essential oil of Citrus aurantium L. at doses of $0.5,2.5$, and 5 percent, increases the time spent in open arms. Also, significant differences were observed between the groups that received doses of 2.5 and 5 percent and control group in the time spent in open arms $(P<0.001)$; this difference was less in the group that received lower dose $(P<0.05)$.

Figure 2 illustrates that intraperitoneal injection of fluoxetine $(2 \mathrm{mg} / \mathrm{kg})$ results in increased spent time in open arms. Significant differences were observed between experimental group and control group $(P<0.001)$. Injection of essential oil of Citrus aurantium L. along with fluoxetine (at doses of $0.5,2.5$, and 5 percent) resulted in significant increased spent time in open arms $(P<0.001)$.

Figure 3 illustrates that intraperitoneal injection of essential oil of Citrus aurantium L. (at dose of 5 percent) results in significant differences ${ }^{*} P<0.05$ between experimental group and control group in the number of entries to the open arms.

Figure 4 illustrates that intraperitoneal injection of fluoxetine $(2 \mathrm{mg} / \mathrm{kg})$ results in increased number of entries to the open arms. Significant differences were observed between the experimental groups and control group in the number of entries to the open arms $(P<0.001)$. Also, the injection of Citrus aurantium L. (at doses of 0.5,

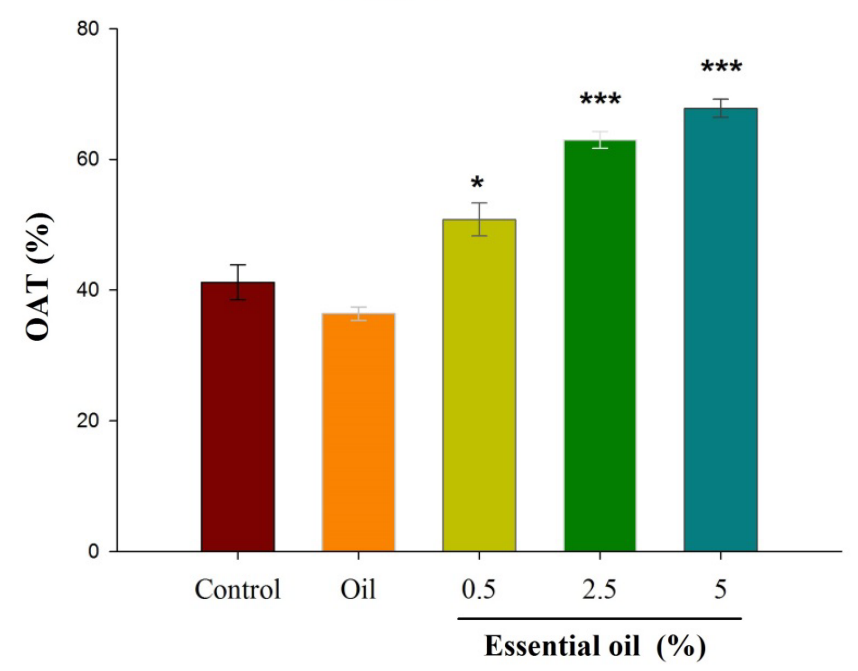

Figure 1. Comparison between experimental groups (received essential oil of Citrus aurantium L. at doses of $0.5,2.5$, and 5 percent), control and sham groups (received olive oil) in antianxiety effect of Citrus aurantium L. essential oil. Mean \pm S.E.M. $n=$ 6. ${ }^{*} P<0.05$ and ${ }^{* * *} P<0.001$. OAT is the spent time in open arms. 


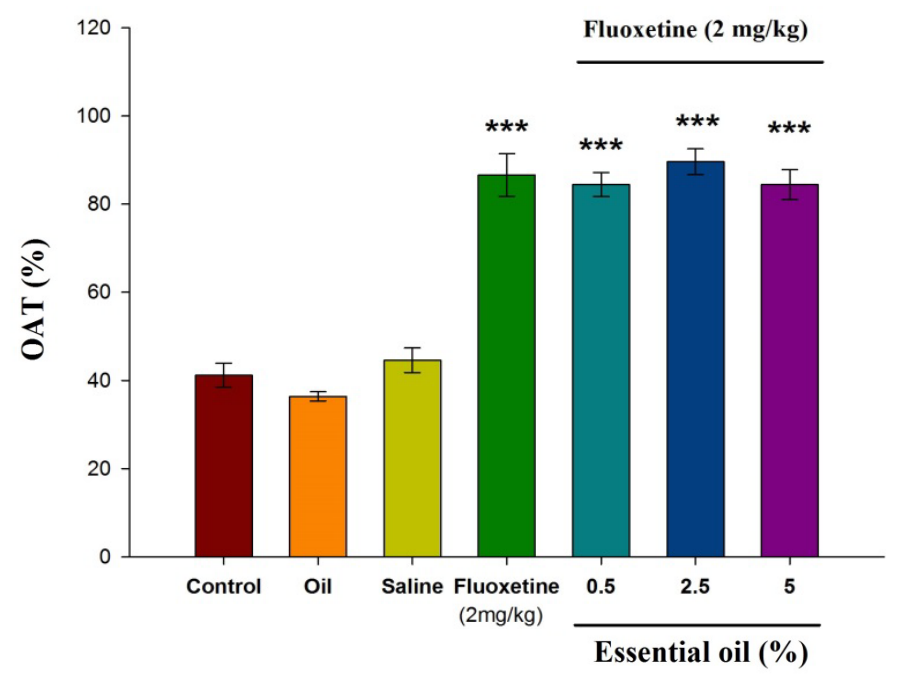

Figure 2. Comparison between experimental groups (received essential oil of Citrus aurantium L. at doses of $0.5,2.5$, and 5 percent along with fluoxetine), control group and sham group (received olive oil) in antianxiety effect of Citrus aurantium L. essential oil. Mean \pm S.E.M. $n=6 .{ }^{* * *} P<0.001$. OAT is the spent time in open arms.

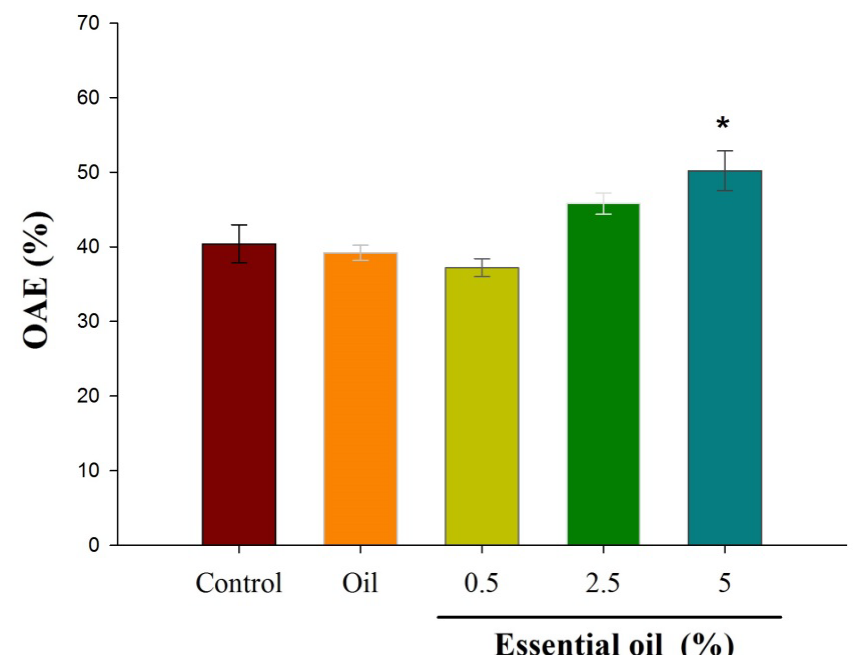

Figure 3. Comparison between experimental groups (received essential oil of Citrus aurantium L. at doses of $0.5,2.5$, and 5 percent), control group and sham group (received olive oil) in antianxiety effect of Citrus aurantium L. essential oil. Mean \pm S.E.M. $n=6$. ${ }^{*} P<0.05$. OAE is the number of entries to the open arms.

2.5, and 5) along with fluoxetine resulted in significant increased number of entries to the open arms in the experimental group compared with the control group $(P<0.001)$.

\section{Discussion}

The results revealed that applying Citrus aurantium L. alone or along with fluoxetine affect the anxiety behavior in mice.

The role of serotonin in changing anxiety behavior has been shown in previous studies. The reduction of serotonin in the synaptic cleft results in increased anxiety disorders and depression. The shortage of serotonin is not the only reason of development of anxiety disorders [8]. Preclinical studies have proposed that through agonist and antagonist drugs, specific 5-HT receptors may increase anxiloytic responses. Several studies have shown that antagonists of 5-HT3 receptor have a role in mood and anxiety disorders [9]. 


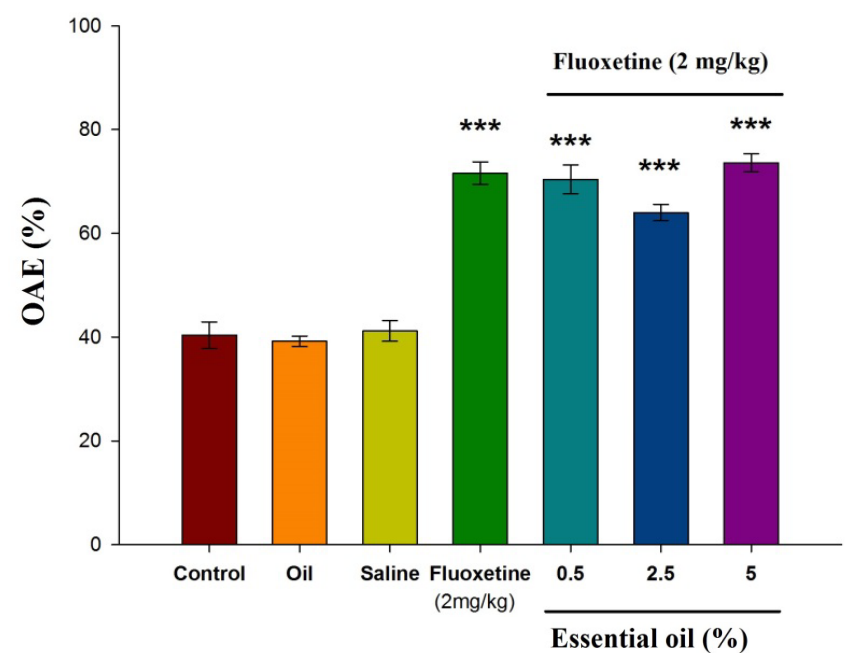

Figure 4. comparison between experimental groups (received essential oil of Citrus aurantium L. at doses of $0.5,2.5$, and 5 percent along with fluoxetine), control group and sham group (received olive oil) in antianxiety effect of Citrus aurantium L. essential oil. Mean \pm S.E.M. $n=6 .{ }^{* * *} P<0.001$. OAE is the number of entries to the open arms.

5-HT3 receptors distributed in amygdala have a key role in the physiopathology of anxiety [10]. The local injection of 5-HT3 receptor antagonists in the amygdala of mice resulted in decreased responses while 5-HT3 receptor agonists showed the opposite effect [11].

According to different studies and based on our previous experimental experiences, it is decided to use low dose of fluoxetine $(2 \mathrm{mg} / \mathrm{kg})$ that shows anxiolytic effects, and thirty minutes interval for injections considered for complete absorption of injected materials. In this study, apparently, fluoxetine $(2 \mathrm{mg} / \mathrm{kg})$ acted as 5-HT3 receptor agonist. According to the results, intraperitoneal injection of fluoxetine into the mice results in the increased number of entries to the open arms $(P<0.001)$ and the spent time in open arms. Also, this study investigated the antianxity effect of Citrus aurantium L. and its interference in serotonergic pathway. As shown in the Figures 1-4, different doses of essential oil Citrus aurantium L. result in increased spent time in open arms dose-dependently. In terms of the number of entries to the open arms, only at a dose of 5 percent there was a significant difference between the experimental group and control group $(P<0.05)$.

It is reported that fluoxetine prevents the connection of 5HT-3 receptor antagonists [12]. However some other studies showed that fluoxetine blocks the release of 5-HT from dorsal raphe nucleus [13].

Citrus aurantium L. contains various compounds that have positive effects on organs' activity, especially in the nervous system. The antianxiety effects of Citrus aurantium L. have been investigated in some studies. Carvalho et al. (2002) have reported that Citrus aurantium L. potentiates the sleep caused by barbiturates and reduces anxiety [14]. Mahmoudi et al. (1384) investigated that flavonoids in Citrus aurantium L. have antianxiety and tranquilizing effects [15]. Also, Lehner (2000) reported that the spray of Citrus aurantium L. essential oil in a dental office leads to decreased anxiety of patients [7]. Shabanian et al. (1387) showed that Citrus aurantium L. can be applied as a premedication to reduce the anxiety of patients before surgery [16]. Citrus aurantriun contains various compounds such as linanol, linalyl acetate, myrcene, limonene, and flavonoids [17]. Antianxiety effects of some of these compounds individually, also have been reported. Limonene reduces the activity of the central nervous system and decreases anxiety [18]. Another study has reported that limonene and myrcene exhibit inhibitory actions in the central nervous system and has antianxiety and antiepileptic effects through suppressing the central nervous system [19]. Other anxiolytic compound of Citrus aurantium L. is coumarin. Pereira (2009) reported that coumarin can have a specific inhibitory effect on the central nervous system and prevent epileptic attacks and seizures [20]. Linanol inhibits the release of acetylcholine and has antiepileptic effects [19]. Generally, flavonoids affect benzodiazepine receptors and result in suppression of nervous system [15].

\section{Conclusion}

It is concluded that certain compounds of Citrus aurantium L. reinforce serotonergic pathways and increase the effect of serotonin in synaptic clefts, which leads to maintain tranquility and reduce the anxiety of laboratory 
animals.

\section{Acknowledgements}

We would like to thank Dr. Hedayat Sahrai for his valuable help and guide.

\section{References}

[1] Brown, G.W. and Harris, T.O. (1989) Depression. In Brown, G.W. and Harris, T.O., Eds., Life Events and Illness, The Guilford, New York, 49-93.

[2] Kulkarni, S.K., Singh, K. and Bishnoi, M. (2008) Comparative Behavioural Profile of Newer Antianxiety Drugs on Different Mazes. Indian Journal of Experimental Biology, 46, 633-638.

[3] Aghajanian, G.K. and Sanders-Bush, E. (2002) Serotonin. Neuropsychopharmacology, 35, 15-35.

[4] Hagerman, R.J. (1999) Neurodevelopmental Disorders: Diagnosis and Treatment. Oxford University Press, Oxford.

[5] Karimi, E., Oskoueian, E., Hendra, R., Oskoueian, A. and Jaafar, H. (2012) Phenolic Compounds Characterization and Biological Activities of Citrus aurantium Bloom. Molecules, 17, 1203-1218. http://dx.doi.org/10.3390/molecules17021203

[6] Costa, C.A., Cury, T.C., Cassettari, B.O., Takahira, R.K., Flório, J.C. and Costa, M. (2013) Citrus aurantium L. Essential Oil Exhibits Anxiolyticlike Activity Mediated by 5-HT1A-Receptors and Reduces Cholesterol after Repeated Oral Treatment. BMC Complementary and Alternative Medicine, 13, 42. http://dx.doi.org/10.1155/2013/841580

[7] Lehrner, J., Eckersberger, C., Walla, P., Pötsch, G. and Deecke, L. (2000) Ambient Odor of Orange in a Dental Office Reduces Anxiety and Improves Mood in Female Pacients. Physiology Behavior, 71, 83-86. http://dx.doi.org/10.1016/S0031-9384(00)00308-5

[8] Turner, E.H., Loftis, J.M. and Blackwell, A.D. (2006) Serotonin a la carte: Supplementation with the Serotonin Precursor 5-Hydroxytryptophan. Pharmacology \& Therapeutics, 109, 325-338. http://dx.doi.org/10.1016/j.pharmthera.2005.06.004

[9] Artigas, F., Adell, A. and Celada, P. (2006) Pindolol Augmentation of Antidepressant Response. Current Drug Targets, 7, 139-147. http://dx.doi.org/10.2174/138945006775515446

[10] Ninan, P.T. (1999) The Functional Anatomy, Neurochemistry, and Pharmacology of Anxiety. Journal of Clinical Psychiatry, 60, 12-17.

[11] Higgins, G.A., Jones, B.J., Oakley, N.R. and Tyers, M.B. (1991) Evidence That the Amygdala Is Involved in the Disinhibitory Effects of 5-HT3 Receptor Antagonists. Psychopharmacology (Berlin), 104, 545-551. http://dx.doi.org/10.1007/BF02245664

[12] Lucchelli, A., Santagostino-Barbone, M.G., Barbieri, A., Candura, S.M. and Tonini, M. (1995) The Interaction of Antidepressant Drugs with Central and Peripheral (Enteric) 5-HT3 and 5-HT4 Receptors. British Journal of Pharmacology, 114, 1017-1025. http://dx.doi.org/10.1111/j.1476-5381.1995.tb13307.x

[13] Bagdy, E., Solyom, S. and Harsing Jr., L.G. (1998) Feedback Stimulation of Somatodendritic Serotonin Release: A 5-HT3 Receptor-Mediated Effect in the Raphe Nuclei of the Rat. Brain Research Bulletin, 45, 203-208. http://dx.doi.org/10.1016/S0361-9230(97)00340-7

[14] Carvalho-Freitas, M.I. and Costa, M. (2002) Anxiolytic and Sedative Effects of Extracts and Essential Oil from Citrus aurantium L. Biological Pharmaceutical Bulletin, 25, 1629-1633.

[15] Mahmoudi, M., Shamsi, M., Froumadi, A. Raftari, Sh. and Asadi Shekari, M. (2005) The Effects of Essential Oil of Citrus aurantium on the Prevention of Pseudo Depression Caused by the Injection of Lipopolysaccharide in Rats. Kerman Medical Sciences Journal, 12, 244-251.

[16] Shabanian, Gh., Pouria Monfared E. and Akhlaghi M. (2008) A Comparison between the Effects of Citrus au-rantium and Diazepam on Reducing Anxiety before Surgery. Shahrekord Medical Sciences University Magazine, 4, 13-18.

[17] Lopes Campêlo, L.M., Gonçalves e Sá, C., de Almeida, A.A.C., et al. (2011) Sedative, Anxiolytic and Antidepressant Activities of Citrus limon (Burn) Essential Oil in Mice. Pharmazie, 66, 623-627.

[18] Re, L., Barocci, S., Sonnino, S., et al. (2000) Linalool Modifies the Nicotinic Receptor-Ion Channel Kinetics at the Mouse Neuromuscular Junction. Pharmacological Research, 42, 177-181. http://dx.doi.org/10.1006/phrs.2000.0671

[19] Deckers, C.L.P., Genton, P., Sills, G.J. and Schmidt, D. (2003) Current Limitations of Antiepileptic Drug Therapy: A Conference Review. Epilepsy Research, 53, 1-17. http://dx.doi.org/10.1016/S0920-1211(02)00257-7

[20] Pereira, E.C., Lucetti, D.L. and Barbosa Filho, J.M. (2009) Coumarin Effects on Amino Acid Levels in Mice Prefrontal Cortex and Hippocampus. Neuroscience Letters, 454, 139-142. http://dx.doi.org/10.1016/j.neulet.2009.03.009 
Scientific Research Publishing (SCIRP) is one of the largest Open Access journal publishers. It is currently publishing more than 200 open access, online, peer-reviewed journals covering a wide range of academic disciplines. SCIRP serves the worldwide academic communities and contributes to the progress and application of science with its publication.

Other selected journals from SCIRP are listed as below. Submit your manuscript to us via either submit@scirp.org or Online Submission Portal.
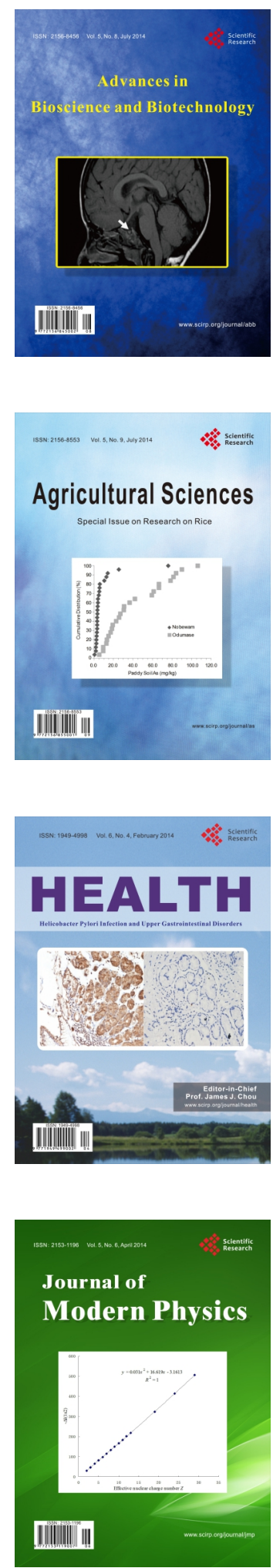
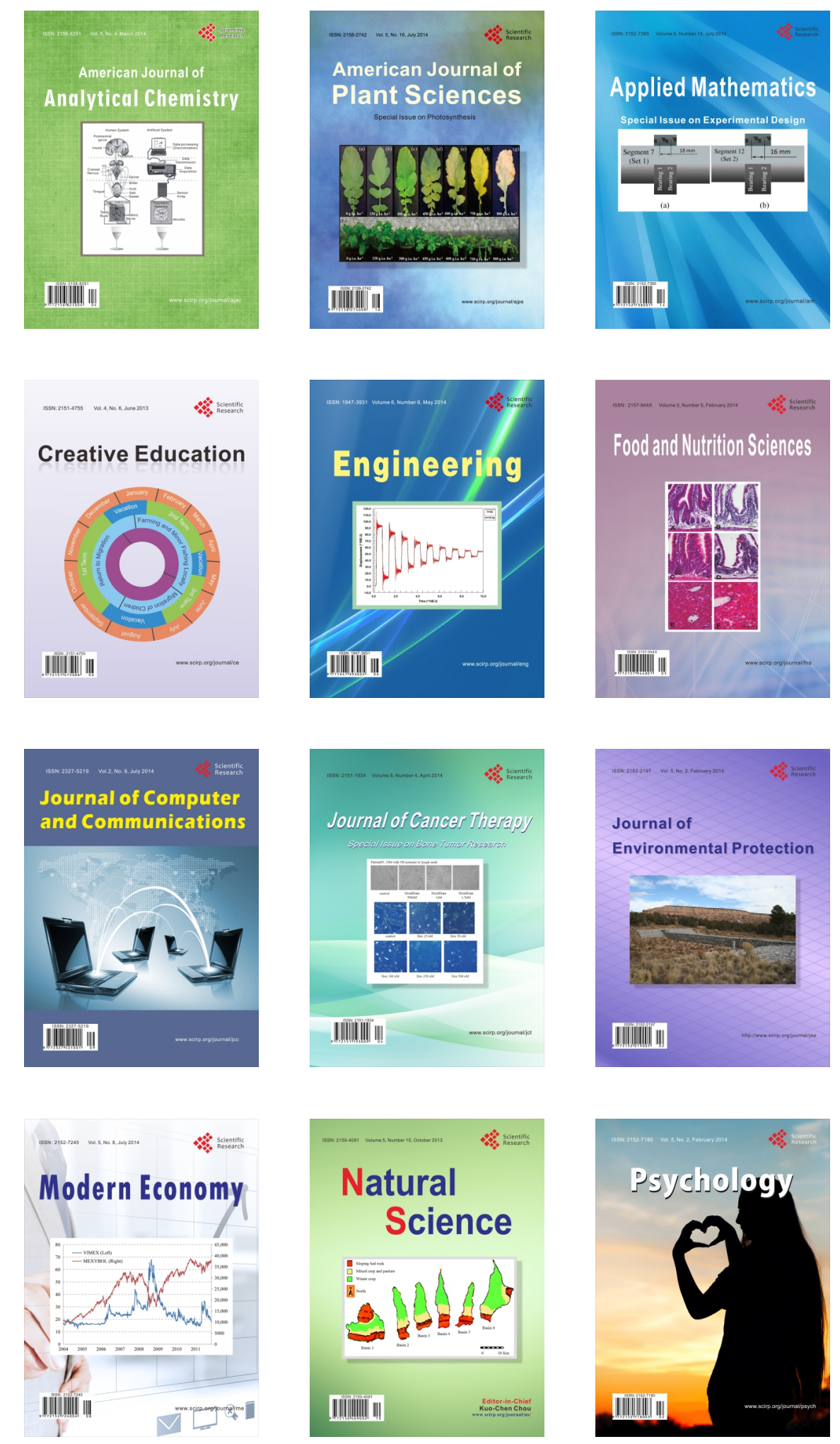